\title{
就 \\ Mechanism and control of roof fall and support failure incidents occurring near longwall recovery roadways
}

\author{
by W. Zhu*, J. Xu**, and G. Xü
}

\section{Synopsis}

Pre-driven longwall recovery roadways are commonly adopted for rapid extraction in the high-production mines of Shendong coalfield in China. A special roadway, the adapting roadway, is utilized to adapt the longwall roof and floor to match the recovery roadway. However, severe accidents such as roof falls and support failures frequently occurred where this recovery roadways layout was applied to relatively deep coal seams. This posed a serious threat to safe production, and effective recovery and relocation of the longwalls. By analysing different cases and mining conditions, theoretical investigation and numerical simulation were conducted based on the mechanisms of such incidents, and a systematic control approach was proposed. The controls involve a method to determine the applicability of the adapting roadway, the evaluation of incident potential, the means to reduce the likelihood of incidents, and an optimized method to determine the location of mesh installation. The findings were applied to multiple longwall faces in the Shendong coalfield and resulted in substantial benefits. The study findings and the proposed control approach can also be applied to other mines with similar problems. Keywords

Shendong coalfield, pre-driven longwall recovery roadway, roof fall, support failure, adapting roadway, flexible mesh.

\section{Introduction}

As one of the eight largest coalfields in the world, the Shendong coalfield in China is typically characterized by shallow cover depth, simple geological conditions, and high coal quality. Shenhua Shendong Coal Group, the largest coal enterprise located in the coalfield, has established massive, fully mechanized longwall faces with a $10 \mathrm{Mt}$ annual output. The technology of pre-driven longwall recovery roadways allows for the safe and rapid movement of equipment in longwall faces. This shortens the time required for longwall moves and substantially increases production (Barer and Listak, 1989; Liu and Chen, 1999).

Figure 1 shows the entry layout for longwall moves. Two entries that are perpendicular to the mining roadways are predriven near the stop line. The one close to the longwall face is called the main longwall recovery roadway, while the other is the secondary longwall recovery roadway. The two entries are connected with several crosscuts. In practice, the floor level at the working face usually does not match the level of the main longwall recovery roadway when the longwall face approaches the main longwall recovery roadway. The level of the longwall floor is either higher or lower than that of the longwall recovery roadway, which causes difficulties in extracting the longwall equipment. This is a common occurrence when the mining height exceeds the height of the longwall recovery roadway. This is because when the longwall face approaches the recovery roadway, the mining height needs to be reduced for the smooth extraction of equipment. The traditional way of matching the roof and floor of the longwall and recovery roadway is to measure the level of the longwall floor at every specific distance from the longwall recovery roadway (for example, $20 \mathrm{~m}, 18 \mathrm{~m}, 16 \mathrm{~m}$, etc.). Then, by adjusting the mining height, the level of the longwall roof can also be well controlled. This is an effective, but timeconsuming method. The use of the adapting roadway allows the miner to control the coal cutter so as to adjust the level of the longwall floor. This is a more efficient method and operation. To avoid roof falls and to ensure the safety of underground personnel, flexible mesh is usually installed at 15 to $20 \mathrm{~m}$ from the stop line.

As shallow coal resources are becoming depleted, the company has started to mine the deeper coal seams. Several longwall faces experienced rib spalling, gangue leak, and even roof fall accidents near the main longwall recovery roadways. In some severe instances, hydraulic cylinders were damaged and the longwall shearer became stuck due to roof fall. This posed serious threats to safe production

* Key Laboratory of Deep Coal Resource Mining, Ministry of Education of China; School of Mines, China University of Mining and Technology, China.

$\uparrow$ Department of Mining Engineering and Metallurgical Engineering, Curtin University, Western Australia, Australia.

‡ Corresponding Author.

(c) The Southern African Institute of Mining and Metallurgy, 2017. ISSN 2225-6253. Paper received Oct. 2016; revised paper received Mar. 2017. 


\section{Mechanism and control of roof fall and support failure incidents}

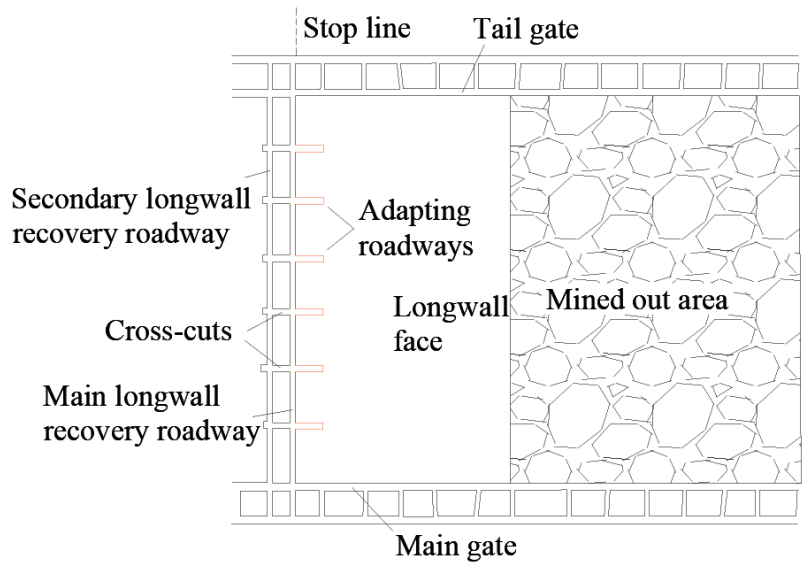

Figure 1-Layout of recovery roadways in Shendong coalfield

and successful removal of the equipment. Therefore, studying the mechanism of hydraulic support failure and roof fall in such conditions, and identifying feasible remedies, became urgent.

The technology of pre-driven longwall recovery roadways has been generally adopted due to its massive advantages (Barer and Listak, 1989; Liu and Chen, 1999), and the systematic assessment for it has been well-developed (Barczak, 2006; Wichlacz, Britten, and Beamish, 2009). With regard to roof management, numerous researchers have conducted in-depth, systematic studies on the design parameters for weak roof conditions (Tadolini, Zhang, and Peng, 2002; Zhang et al., 2006; Lu, 2014; Kang et al., 2015) and the relationship between the supporting system, strata movement, and ground subsidence (Tadolini and Barczak, 2006, 2008; Barczak, Chen, and Bower, 2003; Barczak, Tadolini, and Zhang 2006). The studies on mining-induced stress transfer, roof control technology, and the design of a support system have had a significant instructive effect on the application of pre-driven longwall recovery roadways in the field. The immediate roofs of the longwall recovery roadways in Shendong coalfield are commonly supported by intensive, high-powered hydraulic supports, resulting in fewer roof falls or leaks. However, because of the application of the adapting roadways, severe incidents such as hydraulic support failure and roof fall are more likely to occur when longwall faces approach the main longwall recovery roadways. Many past researchers focused on the study of roof fall at the longwall faces under conditions such as composite single key stratum with thick drift sand (Huang, 2002; Hou, 2000; Shi and Hou, 1996), the uphill section of valley terrains (Xu et al., 2009, 2012; Zhu, 2011), and the mining of the upper pillars (Ju and $\mathrm{Xu}, 2013$; Ju, $\mathrm{Xu}$, and Zhu, 2015; Chen, 2014). However, few studies have focused on the support failures and roof fall incidents that occurred near the longwall recovery roadways.

Based on the above analysis and several incidents in the Shendong coalfield, we present the reasons for and mechanisms of support failure and roof fall incidents that occurred near the longwall recovery roadways, and propose comprehensive prevention countermeasures by using field observation, theoretical analysis, and FLAC3D simulation. The outcome of this study has been successfully applied in Shendong coalfield for the prevention of incidents.

\section{Incident case studies}

\section{Incident 1 - longwall 12401 and longwall 12402, Bulianta coal mine}

Longwall 12401 and longwall 12402 of Bulianta coal mine were deployed at No.4 panel,1-2 coal seam. The coal seam is subhorizontal with a dip angle ranging from $1^{\circ}$ to $3^{\circ}$. The mining height is approximately $4.3 \mathrm{~m}$. The depth of cover near the longwall recovery roadway is between 253 and $260 \mathrm{~m}$. The layout of the panel and entries is illustrated in Figure 2. The distances between the two longwall recovery roadways in longwall 12401 and longwall 12402 were $30 \mathrm{~m}$ and $35 \mathrm{~m}$, respectively. The adapting roadways were $15 \mathrm{~m}$ long and $5 \mathrm{~m}$ wide. There were only two adapting roadways near the main gate in longwall 12401. Other parameters are shown in Figure 2.

When longwall 12401 face retreated $13 \mathrm{~m}$ from the main longwall recovery roadway, roof fall started above the no. 9020 hydraulic supports (near the adapting roadway). Figure 2

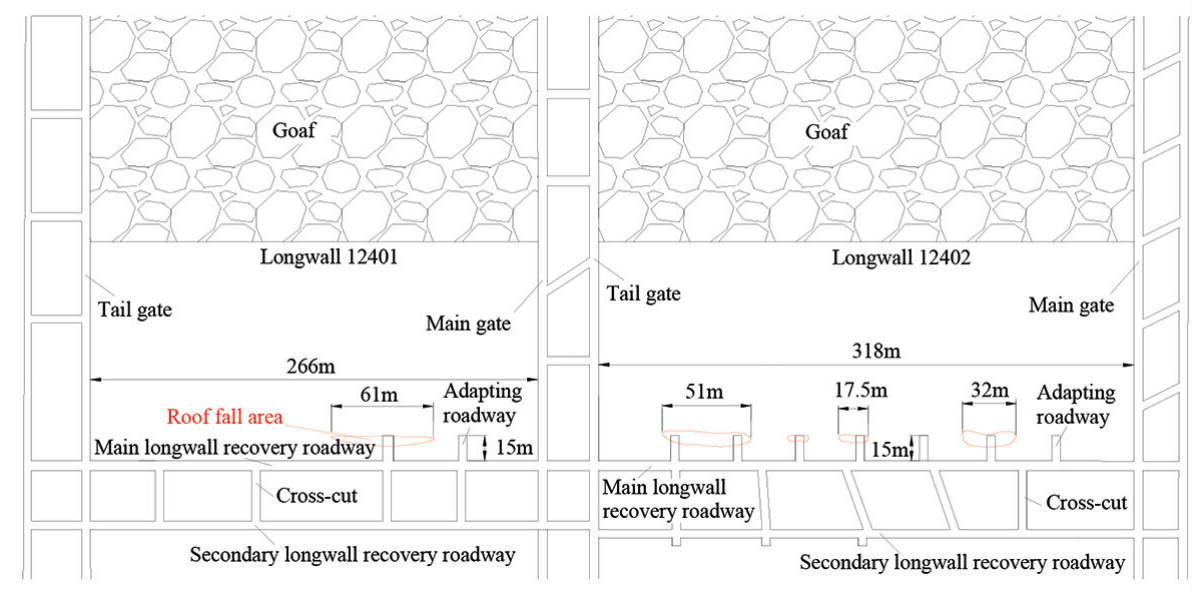

Figure 2-Roof fall areas and roadway layout of longwalls 12401 and 12402 


\section{Mechanism and control of roof fall and support failure incidents}

shows the roof fall areas. The height of roof fall was between $1.0 \mathrm{~m}$ and $1.5 \mathrm{~m}$. Such issues were very serious until the longwall face retreated to $7 \mathrm{~m}$ away from the main longwall recovery roadway. By injecting Marithan, a special coal strengthening grout, into the longwall face, the coal mass was stabilized and the face eventually completed extraction.

Similarly, in longwall 12402 face, roof fall occurred in multiple parts of the roof near the adapting roadways when the face retreated to $12.5 \mathrm{~m}$ from the main longwall recovery roadway. The roof fall areas were $1.5 \mathrm{~m}$ to $2.2 \mathrm{~m}$ high and $1.0 \mathrm{~m}$ to $1.7 \mathrm{~m}$ wide (refer to Figure 2). Injection of Marithan did not control the roof fall, and extraction of the longwall could not be completed until mining personnel upgraded the support by adding bolts and anchor cables.

\section{Incident 2 - longwall 52304, Daliuta coal mine}

Longwall 52304 was the first panel with $7.0 \mathrm{~m}$-high support in 5-2 coal seam of Daliuta coal mine in Shendong coalfield. The coal seam has a dip angle ranging from $1^{\circ}$ to $3^{\circ}$. The longwall 52304 panel was $4547.6 \mathrm{~m}$ long and $301 \mathrm{~m}$ wide, with a cover depth of $275 \mathrm{~m}$ near the main longwall recovery roadway. The adapting roadways were $20 \mathrm{~m}$ long and $4 \mathrm{~m}$ wide. The width of the main longwall recovery roadway was $6.8 \mathrm{~m}$, and it was separated from the secondary longwall recovery roadway by 20 m pillars (refer to Figure $3 \mathrm{a}$ ).

On 6 March 2013, mining at the longwall face stopped $20 \mathrm{~m}$ from the main longwall recovery roadway to wait for ground pressure to be established. The pressure did not appear, so the mining personnel decided to resume operation on the morning of 7 March. Periodic roof pressure manifested when the longwall face was retreated to $17.5 \mathrm{~m}$ away from the main longwall recovery roadway, when the flexible mesh was installed. On the afternoon of 8 March, there was a serious compressive closure of hydraulic cylinders in the no. 39 to no. 108 supports; and the available compression distance was less than $1 \mathrm{~m}$ for supports no. 86 to no. 88 , causing inadequate space for the longwall shear and serious gangue leakage. From 9 to 22 March, due to the severe roof fall in the longwall face, the major work consisted mainly of the disposal of the massive stone blocks and the injection of Marithan grout into the coal mass. During that time, production was further delayed by many hours due to the breakdown of conveyor and transfer machines, thus only about $10 \mathrm{~m}$ (to $7 \mathrm{~m}$ from the main longwall recovery roadway) could be extracted. After the night shift on 23 March, the centre section of the longwall face remained $6 \mathrm{~m}$ from the main longwall recovery roadway, and workers continued hanging and fixing flexible mesh. The longwall face approached the end of the panel and finished production on 25 March.

\section{Incident statistics and analysis}

From the above cases studies, it can be seen that the roof fall incidents occurred mainly near the adapting roadways; and the support failures occurred due to the roof falls. The cause of the incidents can therefore be preliminarily attributed to the adapting roadways. A summary of the 51 longwall panels in the Shendong coalfield is listed in Table I for comparison. It can be seen that the widths and lengths of the adapting roadways in Shendong coalfield are generally 3 to $5 \mathrm{~m}$ and 10 to $20 \mathrm{~m}$, respectively. With similar supporting systems, roof fall and support failure occurred only when the longwall panel depth was large. Therefore, the use of adapting roadways at greater than a certain depth may be the major possible cause. This hypothesis is further investigated by theoretical analysis and numerical modelling in the following sections.

\section{Mechanism analysis}

\section{Theoretical analysis}

The stress over the adapting roadway will transfer to the adjacent coal mass and cause abutment stress. The area outside the peak position of the abutment pressure is called the plastic zone. The coal mass near the wall has a lower

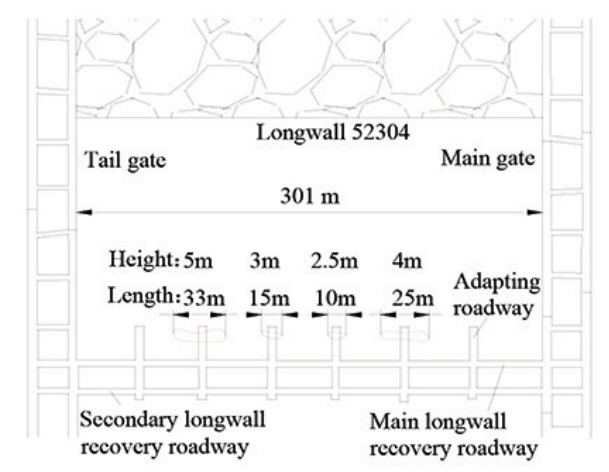

(a) Roof fall areas of longwall 52304

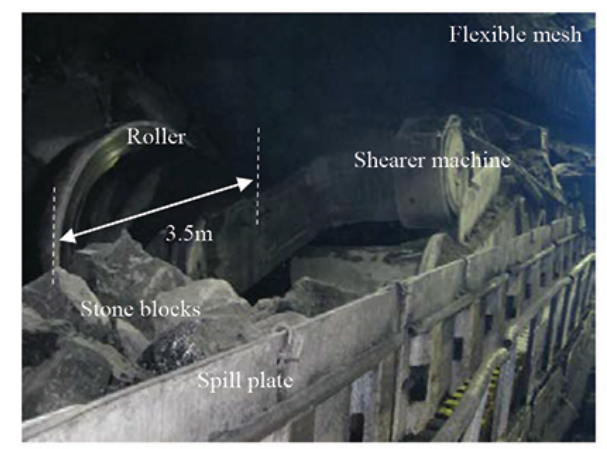

(b) The shearer was stuck

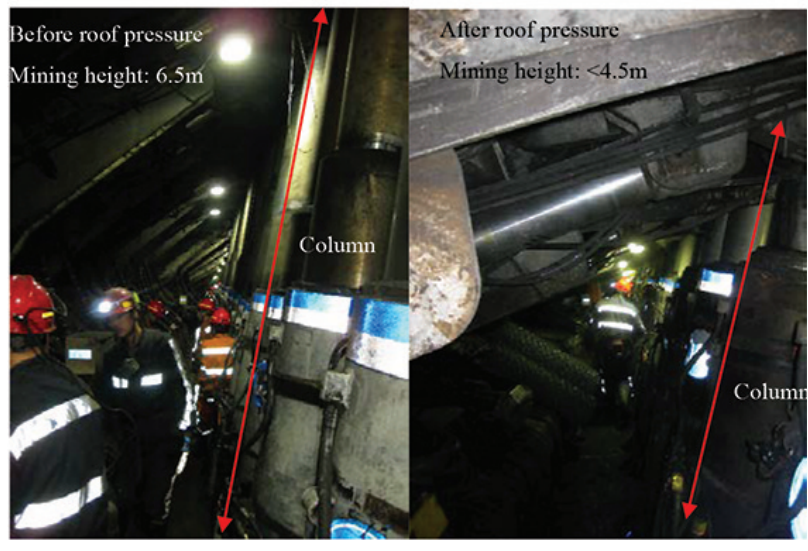

(c) Comparison of mining height before and after roof pressure

Figure 3-Scene of incident in longwall 52304 


\section{Mechanism and control of roof fall and support failure incidents}

\section{Table I}

Adapting roadway parameters and roof fall situation in Shendong coalfield

\begin{tabular}{|c|c|c|c|c|c|}
\hline Name of longwall faces & Mining height/m & Width /m & Length /m & Cover depth/m & Roof fall or not \\
\hline 22608 22615and22302 22309 of Daliuta mine & 4.2 & $3.0 \sim 5.0$ & $12 \sim 17.5$ & $48 \sim 94$ & \\
\hline 22207-2and22302 of Bulianta mine & 6.8 & $3.6,4.5$ & $20,19.2$ & 55,147 & \\
\hline 12up201 12up208and22301 22306 of Huojitu mine & 4.5 & $3.0 \sim 5.0$ & $12 \sim 17.5$ & $61 \sim 102$ & \\
\hline $12201 \sim 12203$ of Shangwan mine & 7.0 & 3.3 & $10 \sim 12$ & 72 87 & \multirow{2}{*}{ No } \\
\hline 12103 12105and12201 12206 of Shigetai mine & 3.5 & $3.3 \sim 5.2$ & 10 18 & 77 98 & \\
\hline $31406,31110-1$ of Wulanmulun mine & 4.4 & No adapting roadway & 190 & & \\
\hline $42104,42103-1$ of Buertai mine & 6.7 & No adapting roadway & 259,278 & & \\
\hline 12401,12402 of Bulianta mine & $4.2 \sim 4.4$ & 5.0 & 15 & 253,260 & \multirow{2}{*}{ Yes } \\
\hline 52304 of Daliuta mine & 7.0 & 5.0 & 20 & 275 & \\
\hline
\end{tabular}

stress than the in situ stress, and this area is called the fractured zone (Qian, Shi, and $\mathrm{Xu}, 2010$ ) (refer to Figure 4). If $x_{0}$ denotes the width of the plastic zone and the stress distribution in the plastic zone is assumed as linear, the width of the fractured area can be expressed as:

$$
x=\frac{x_{0}}{K}=\frac{m}{2 K \xi f} \ln \frac{K \gamma H+C \cot \varphi}{\xi(p+C \cot \varphi)}
$$

where $K$ is the stress concentration factor, $\gamma H$ is overlying strata loading, $p$ is the support resistance in the roadway, $m$ is the thickness of the coal seam, $C$ and $\varphi$ are the cohesion and internal friction angle of the coal, respectively, $f$ is the friction coefficient of the coal seam to roof or floor, $\xi$ is the triaxial stress coefficient, and $\xi=(1-\sin \varphi) /(1+\sin \varphi)$.

Using specific parameters from the Shendong coalfield, the calculated width of the plastic zone is generally more than $9 \mathrm{~m}$. This figure can be up to $20 \mathrm{~m}$ when the cover depth and mining height are relatively large (for instance, their values are $250 \mathrm{~m}$ and $7 \mathrm{~m}$, respectively), with a $5 \mathrm{~m}$ wide fractured zone.

Similarly, the longwall face abutment stress will transfer to the coal mass near the adapting roadway when the longwall face approaches it. This additional stress is more likely to cause the coal mass in the fractured zone (induced by the adapting roadway) to completely lose its bearing capacity. Severe rib spalling will occur at the intersection of the adapting roadway and longwall face due to insufficient support. This can enlarge the hanging area of the roof and result in roof fall. The immediate roof generates the resistance in the hydraulic support to control the movement of the overlying strata. When roof fall reaches a certain extent, the immediate roof cannot impart sufficient resistance to the overlying key block (the broken hard stratum), which may cause the key block to rotate and slide down. The instability of the overlying strata can cause a sudden roof drop and induce a more serious roof fall (refer to Figure 5).

According to Equation [1], there is a positive correlation between the cover depth and the width of the fractured zone, hence the probability and severity of the incident will increase when the cover depth increases. To further analyse the mechanism of the roof fall and support failure in a longwall face caused by the adapting roadway, a further study of the influence of the adaptingroadway on the vertical stress in the coal mass and the deformation of the roadway was conducted, and is described in the next section.

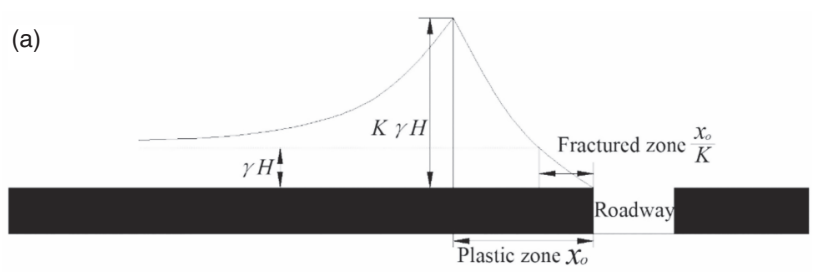

(b) Main longwall recovery roadway

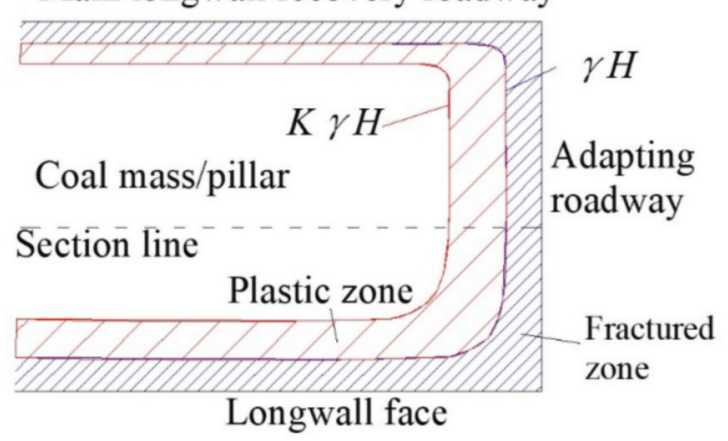

Figure 4-(a) Distribution of vertical stress in coal mass and (b) classification of deformation zone

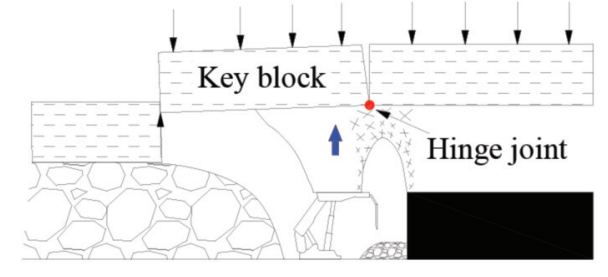

(a) Rib spalling results in roof fall

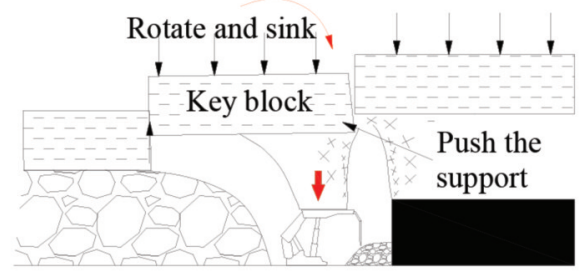

(b) Roof fall triggers support failure

Figure 5-Development of roof fall and support failure 


\section{Mechanism and control of roof fall and support failure incidents}

\section{Numerical simulation}

The finite difference numerical code FLAC3D was used to simulate the influence of the adapting roadway stress distribution. The features of the rock strata were determined according to the actual rock strata in longwall 12401 of Bulianta coal mine and longwall 52304 of Daliuta coal mine, with some reasonable simplifications. The rock mechanics parameters in the model were determined by standard mechanical tests on borehole core samples from several production longwall panels in the Shendong coalfield (refer to Table II).
Four groups of models were established, each with a length, width, and height of $300 \mathrm{~m}, 200 \mathrm{~m}$, and $120 \mathrm{~m}$, respectively (refer to Figure $6 \mathrm{a}$ ). The thicknesses of the coal seam and floor were $5 \mathrm{~m}$ and $20 \mathrm{~m}$, respectively, and the cover depth of the coal seam was $100 \mathrm{~m}$. The support parameters of the adapting roadway were in agreement with the parameters in the field. Table III shows the parameters and layouts of the adapting roadways in the four groups. A uniformly distributed vertical stress with a gradient of 0.025 $\mathrm{MPa} / \mathrm{m}$ was applied to the top interface of the model to represent the overlying strata. The group one models were

Table II

Rock mechanics parameters for numerical simulation

\begin{tabular}{|l|c|c|c|c|c|c|}
\hline Lithology & $\begin{array}{c}\text { Bulk modulus } \\
\text { (Gpa) }\end{array}$ & $\begin{array}{c}\text { Shear modulus } \\
\text { (G)a) }\end{array}$ & $\begin{array}{c}\text { Internal friction angle } \\
\text { ( }{ }^{\circ} \text { ) }\end{array}$ & $\begin{array}{c}\text { Cohesion } \\
\text { (MPa) }\end{array}$ & $\begin{array}{c}\text { Tensile strength } \\
\text { (MPa) }\end{array}$ & $\begin{array}{c}\text { Poisson's } \\
\text { ratio }\end{array}$ \\
weight (kg.m-3)
\end{tabular}

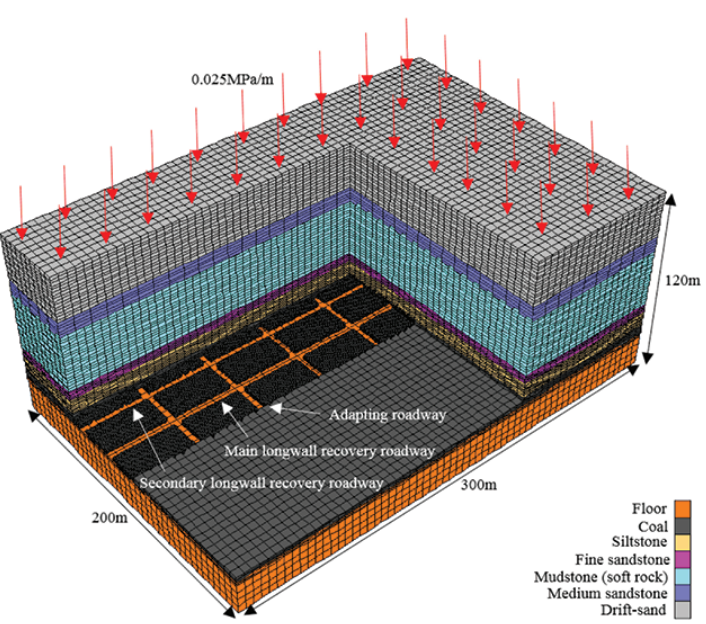

(a) Layout of the numerical model

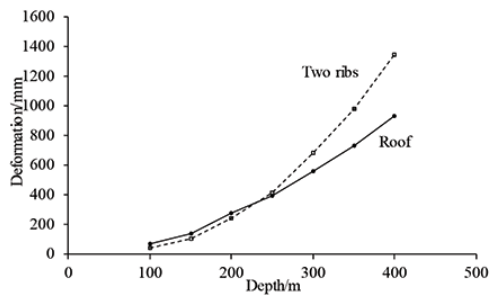

(b) Influence of cover depth on deformation of adapting roadway

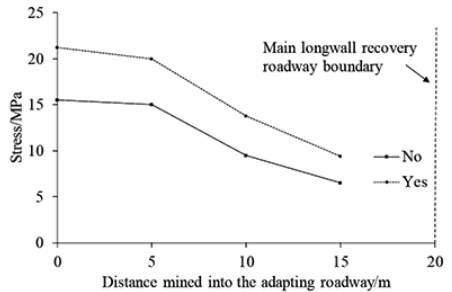

(c) Influence of adapting roadway on vertical stress in coal mass

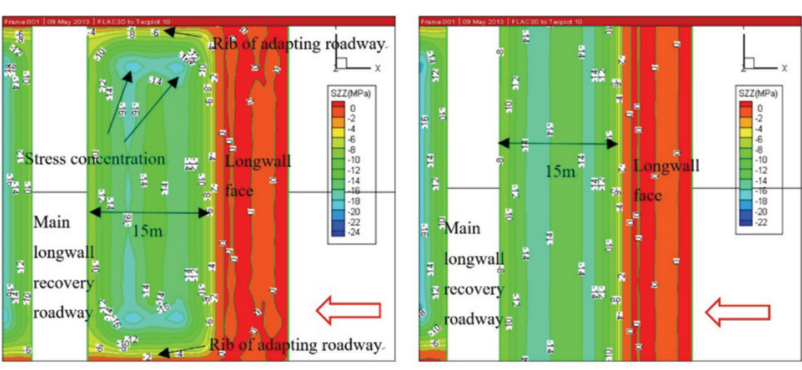

(d) Distribution of vertical stress in coal mass when longwall face was $15 \mathrm{~m}$ away from main longwall recovery roadway

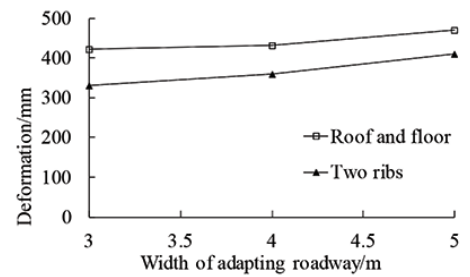

(e) Deformation of adapting roadway in different widths

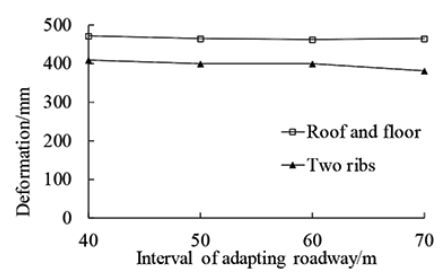

(f) Deformation of adapting roadway in different intervals 


\section{Mechanism and control of roof fall and support failure incidents}

\begin{tabular}{|c|c|c|c|}
\hline \multicolumn{4}{|c|}{$\begin{array}{l}\text { Table III } \\
\text { Parameters and layout of the adapting roadways in four groups }\end{array}$} \\
\hline Group & Cover depth/m & Width /m & Interval /m \\
\hline 1 & $100,150,200,250,300,350,400$ & 5 & 40 \\
\hline \multirow[t]{2}{*}{2} & \multirow{2}{*}{250} & 5 & 40 \\
\hline & & \multicolumn{2}{|c|}{ No adapting roadway } \\
\hline 3 & 250 & $3,4,5$ & 40 \\
\hline 4 & 250 & 5 & $40,50,60,70$ \\
\hline
\end{tabular}

used to simulate the influence of cover depth on the deformation of the adapting roadway. Groups two to four were used to determine the impact of the use or non-use of adapting roadways, the width and interval of the adapting roadway on the vertical stress in the coal mass, and the deformation of the roadway. The dip was not considered because the coal seams in the Shendong coalfield are relatively flat. The bottom boundaryof the model was restricted in vertical movement, and the lateral boundary was restricted in horizontal movement. All the remaining areas, including the coal, roof, and floor, were assumed to have elastic-perfectly plastic behaviour as defined by the MohrCoulomb strength criterion.

Because the study focused mainly on the impact of the adapting roadway on the vertical stress in the coal mass and the deformation of the roadway when the longwall face approached the main longwall recovery roadway, the coal seam that was $40 \mathrm{~m}$ away from the adapting roadway was excavated immediately in the simulation to allow the overlying strata to deform to a steady-state condition. After that, the coal seam was excavated by a $5 \mathrm{~m}$ step in the simulation. Figure 6 shows the results.

The deformations of the roof and two ribs of the roadway increased rapidly with the cover depth (refer to Figure 6b), from $66.9 \mathrm{~mm}$ to $929 \mathrm{~mm}$ and $40 \mathrm{~mm}$ to $1340 \mathrm{~mm}$, respectively, when cover depth increased from $100 \mathrm{~m}$ to $400 \mathrm{~m}$. Figure $6 \mathrm{c}$ and Figure $6 \mathrm{~d}$ show that the adapting roadway has a significant impact on the stress in the coal mass above the longwall face, resulting in the stress concentrating in the intersection of the adapting roadway and longwall face. The stress concentration factor is up to 3.4. Thus, large-scale fracturing of the coal mass will occur when the cover depth increases to a certain degree, which can trigger roof fall. Figure 6e and Figure $6 \mathrm{f}$ show that the width and the interval of the adapting roadway have little impact on deformation. From the results of the simulation, the conclusion can be drawn that the cover depth is a key factor that increases the vertical stress and the deformation of the adapting roadway.

\section{Key factors and countermeasures}

The coal mass in front of the longwall face is divided into several pillars by the adapting roadways, which will increase the degree of stress concentration and impair the bearing capacity of the coal mass. The adapting roadways can also increase the hanging area of the roof, which is very likely to trigger rib spalling and roof fall with increasing cover depth. This poses extreme difficulties for effective roof control. The mining rate is delayed by the installation of flexible mesh, which further increases the challenges of roof control. Based on the analysis in the previous sections, the maximum applicable cover depth of the adapting roadway was determined, and a method was developed to determine the optimum position of flexible mesh installation. Lastly, a flow chart is provided to evaluate the incident potential and to apply different countermeasures

\section{Maximum cover depth of adapting roadway}

The longwall recovery roadways in the Shendong coalfield contain the main and secondary longwall recovery roadways, and the adapting roadways. The main factor triggering support failure and roof fall is the application of the adapting roadway beyond a certain cover depth. The results of numerical simulation indicated that the width and the interval of the adapting roadway have a minimal influence on its deformation. Thus, these parameters cannot be further optimized. However, the deformation of adapting roadways is sensitive to the cover depth, which indicates that there is a maximum depth for the application of adapting roadways.

\section{Maximal cover depth based on the stability of the coal mass}

When the longwall face is mined to the adapting roadway, the coal mass in front of the longwall face is divided into several independent coal pillars. The length of the adapting roadway is generally less than $20 \mathrm{~m}$, and the interval between two roadways is usually more than $30 \mathrm{~m}$. The bearing capacity of coal pillars decreases with the progress of the longwall face. Based on the Obert-Duvall/Wang formula, the strength of the coal pillar can be expressed by:

$$
R=R_{c}\left(0.778+0.222 \frac{B}{h}\right)
$$

where $R, B$, and $h$ are the strength, width, and the height of the coal pillar, respectively; and $R_{\mathcal{C}}$ is the cube compressive strength of the coal.

According to the typical arrangement of adapting roadways in Shendong coalfield, the value of $h$ is $5 \mathrm{~m}$, the length is $20 \mathrm{~m}$, so the initial value of $B$ is $20 \mathrm{~m}$. From tests on massive coal samples from multiple regions in the Shendong coalfield, the value of $R_{\mathcal{C}}$ is determined to be 13.5 $\mathrm{MPa}$. The maximum coal pillar strength can be calculated by using various distances mined into the adapting roadway. This is plotted in Figure 7 together with the maximum stress calculated from the numerical simulation. The figure shows that the stress in the coal pillar is greatest when the longwall 


\section{Mechanism and control of roof fall and support failure incidents}

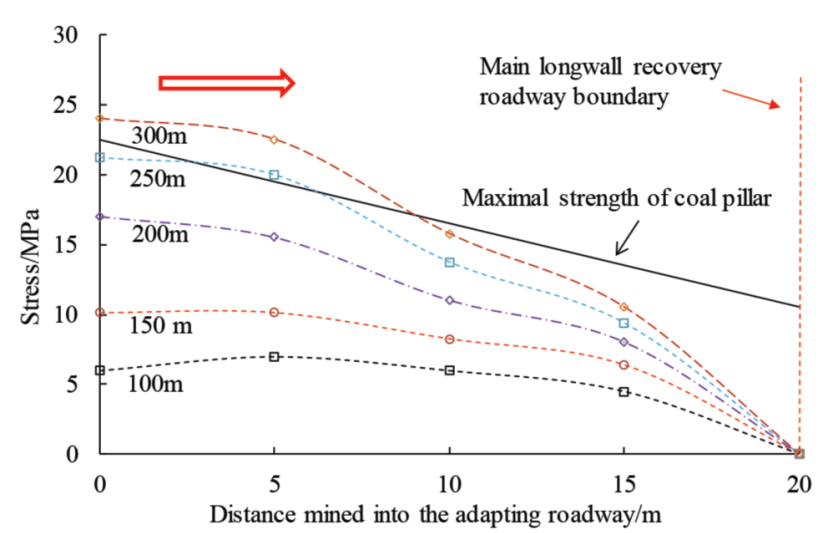

Figure 7-Comparison between stress and strength of coal pillar for different cover depths

face enters the adapting roadways. The advance abutment pressure transfers to the main longwall recovery roadway, or even further, as mining progresses (Kang et al., 2015; Batchler, 2016), hence the stress in the coal pillar shows a downward trend. Therefore, support failure and roof fall are more likely to occur when longwall faces have just entered the adapting roadways. This was demonstrated by the three case studies presented above, in which the incidents occurred when the longwall faces had just entered the adapting roadway by $2 \mathrm{~m}$ to $3 \mathrm{~m}$.

Figure 7 also reveals that when the cover depth reaches $250 \mathrm{~m}$, the stress in the coal pillar exceeds its maximum strength when the longwall face has entered the adapting roadway by $3 \mathrm{~m}$ to $7 \mathrm{~m}$. When the cover depth is less than $200 \mathrm{~m}$, the coal pillar remains in a safe condition. Therefore, the applicable maximum depth of the adapting roadways is determined to be between $200 \mathrm{~m}$ and $250 \mathrm{~m}$.

\section{Maximal cover depth based on roadway deformation}

During the last stage of mining, the longwall face is connected to the main longwall recovery roadway by adapting roadways. The deformation of the adapting roadways is closely related to the stability of coal walls and the roof control. Therefore, for the safe excavation of the longwall face it is critically important to control the deformation of the adapting roadway within a certain range. Table IV shows the level of difficulty in controlling the deformation of roadways (Chen and $\mathrm{Lu}, 1994$ ). According to these criteria, roadway maintenance is relatively easy when the deformation is between $200 \mathrm{~mm}$ and $500 \mathrm{~mm}$. Based on site experience in this coalfield, the roadway is generally considered to be relatively easy to control under shallow cover when the deformation of the roadway is less than $350 \mathrm{~mm}$. This is used as the threshold deformation.

Figure 8 shows the deformation change with cover depth for roof and floor, and ribs. It can be seen that the cover depths corresponding to $350 \mathrm{~mm}$ deformation of the roof, and ribs are $212 \mathrm{~m}$ and $229 \mathrm{~m}$, respectively. Therefore, from the perspective of the difficulty of roadway maintenance, the adapting roadway is inapplicable when the cover depth of the longwall face exceeds $212 \mathrm{~m}$.
Therefore, considering both criteria for coal pillar stability and the manageability of roadway deformation, the applicative maximum depth of the adapting roadways is determined to be $212 \mathrm{~m}$. The existing adapting roadways at greater depths should be considered for backfill (Figure 9a), or a new main longwall recovery roadway should be excavated at the end of the adapting roadways (Figure 9b). For new panels that are deeper than $212 \mathrm{~m}$, the method of drilling holes from the longwall recovery roadway in the direction of the longwall face and filling the holes with lime for marking purposes can be used together with elevation survey methods.

\section{Optimum position of mesh installation}

The flexible mesh is usually installed at a distance of 15 to $20 \mathrm{~m}$ from the main longwall recovery roadway. In the initial period of mesh installation, a large area of the roof is exposed and it is critical to maintain good roof conditions. In practice, workers usually choose an empirical time and location to start installing mesh, which may encounter periodic roof pressure, and trigger support failure and roof fall. For instance, in the case of longwall 52304 in the Daliuta coal

Table IV

Rank of maintenance of underground roadways

\begin{tabular}{|l|c|c|c|c|}
\hline Level & Easy & Medium & Hard & Hardest \\
\hline Deformation of roadway/mm & $<200$ & $200 \sim 500$ & $500 \sim 1000$ & $>1000$ \\
\hline
\end{tabular}

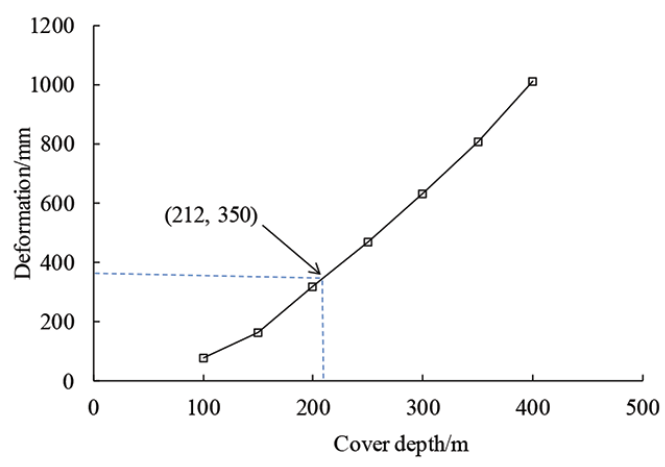

(a) Deformation of roof and floor with different cover depths

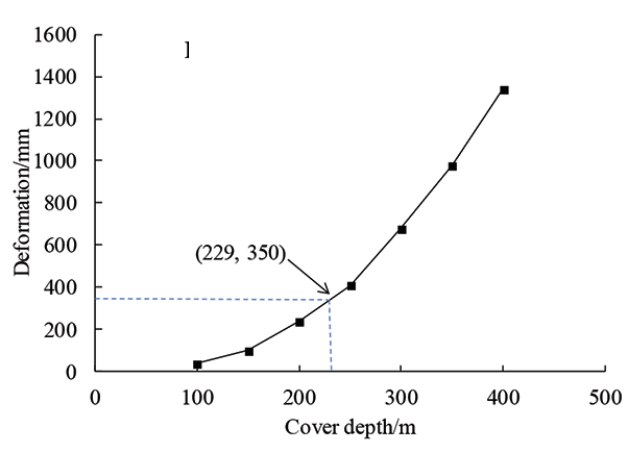

(b) Deformation of two ribs with different cover depths 


\section{Mechanism and control of roof fall and support failure incidents}

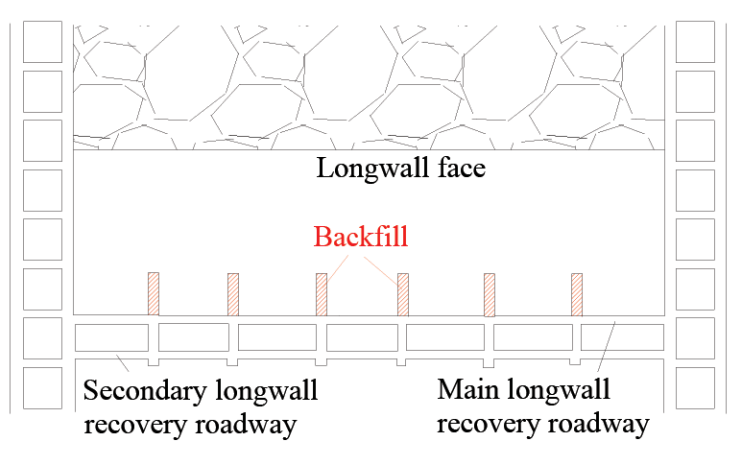

(a) Backfilling the adapting roadways

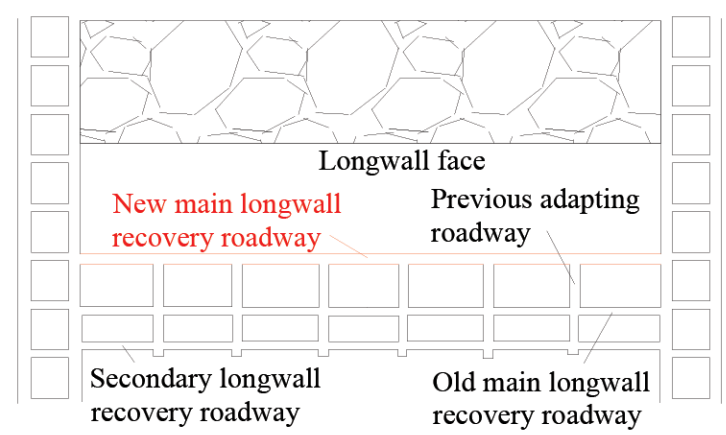

(b) Excavating a new main recovery roadway

Figure 9-Optimization of extraction roadways

mine, mesh installation coincided with the last periodic roof pressure, which aggravated the accident.

Figure 10 illustrates the parameters that are related to mesh installation. By studying multiple mesh installation cases in the Shendong coalfield, the position of the mesh installation can be expressed as:

$$
\left\{\begin{array}{cc}
X=X_{\min } \sim X_{o} & L_{z}<X_{\min } \\
X=L_{z}+n \times d & X_{\min } \leq L_{z}<X_{\min }+L_{c} \\
X=L_{z}-L_{c} & X_{\min }+L_{c} \leq L_{z}
\end{array}\right.
$$

where $X$ is the position of the mesh installation, $X_{\min }$ is the minimum mesh installation length, $X_{0}$ is the maximum mesh installation length (the length of flexible mesh), $L_{z}$ is the position of the last periodic roof pressure from the main longwall recovery roadway, $L_{c}$ is the persistence length of periodic roof pressure, $n$ is an influence coefficient with a value between 2 and 4, and $d$ is the cutting depth of the shearer, which usually equals $0.8 \mathrm{~m}$ in the Shendong coalfield.

The mesh installation needs to consider all the parameters related to ground pressure and the installation method. The periodic roof pressure can be predicted by the observation and analysis of previous periodic roof pressure frequency. If the position of the predicted periodic roof pressure is less than $X_{\min }$, the position of mesh installation can be selected at the miners' discretion between the minimum and maximum mesh installation lengths. However, if the position of the predicted periodic roof pressure is greater than $X_{\min }$ but less than the sum of the maximum mesh installation length and the persistence length of periodic roof pressure, the position of the mesh installation should start 2 to 4 cuts before the predicted periodic roof pressure as mesh installation a relatively time-consuming process. When the position of the predicted periodic roof pressure is greater than the sum of the maximum mesh installation length and the persistence length of periodic roof pressure, the mesh should be installed after the periodic roof pressure. If the length of flexible mesh is insufficient according to this design, metal mesh should be used for continued protection.

\section{Incident potential and prevention}

Incident potential in such conditions can be evaluated based on the study above. The countermeasures are proposed to eliminate risk, and to ensure the safe and smooth excavation of the longwall face. Figure 11 shows a detailed flow chart for evaluation and prevention. The evaluation starts with assessing whether the adapting roadways have been excavated. If they have been excavated, the cover depth should be confirmed to be less than $212 \mathrm{~m}$. Otherwise, the adapting roadways need to be backfilled, or a new main longwall recovery roadway needs to be excavated at the end of the adapting roadways. For flexible mesh installation, the periodic roof pressure should be predicted based on previous periodic roof pressure frequency, and the optimum mesh installation position should be confirmed to ensure safe excavation of the longwall face.

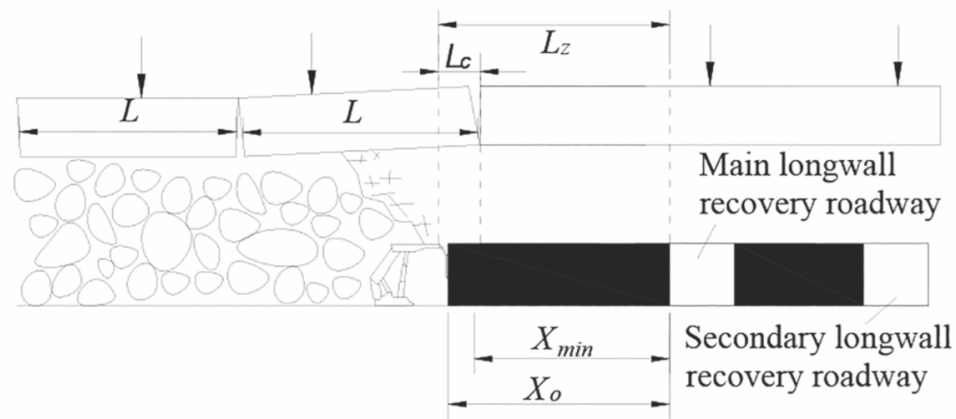




\section{Mechanism and control of roof fall and support failure incidents}

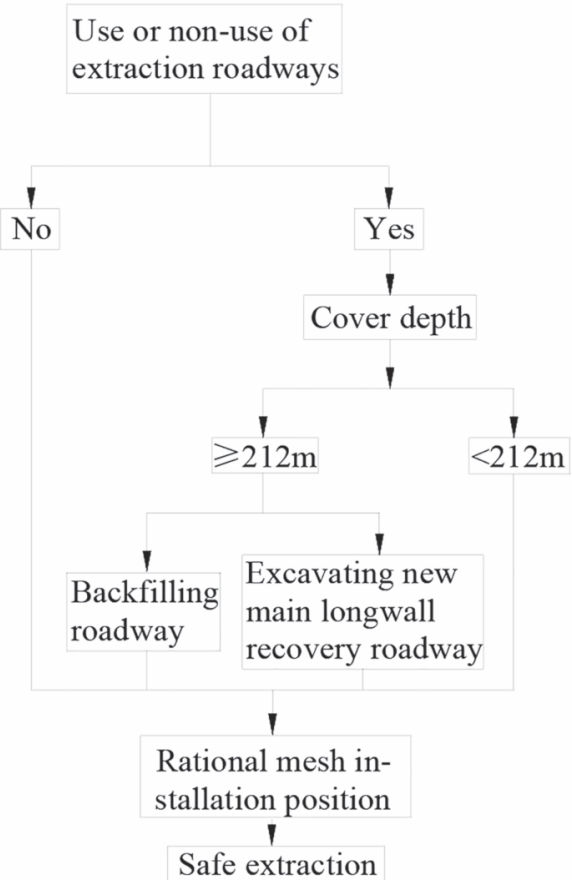

Figure 11-Flow chart of incident potential and prevention

\section{Field trials}

\section{Longwall 12405 and longwall 12406 of Bulianta coal mine}

The geological conditions of longwall 12405 and longwall 12406 of Bulianta coal mine were similar to longwall1 2401, and the adapting roadway of longwall 12405 had been excavated in advance. Considering that the cover depth of the two longwall faces reached $225 \mathrm{~m}$, a new main longwall recovery roadway was excavated at the end of the adapting roadway in longwall 12405 (using the method shown in Figure $9 \mathrm{~b}$ ). Due to the cover depth exceeding the maximum applicable depth determined in the previous section, the adapting roadways were not excavated in longwall 12406, and the width of pillars between the main and secondary longwall recovery roadway was increased. No incidents occurred in both panels, and the production was smooth and rapid.

\section{Longwall 52303 of Daliuta coal mine}

Longwall 52303 was the successive longwall face to longwall 52304 , and the geological conditions of the two longwall faces were the same. Considering that the cover depth of longwall 52303 reached $287 \mathrm{~m}$, a new main longwall recovery roadway was excavated at the end of the pre-driven adapting roadways. The mesh installation was also optimized using the method discussed previously. According to the frequency of the six previous periodic roof pressures, the average step was $17 \mathrm{~m}$ and the persistence length was $4.6 \mathrm{~m}$. The nearest periodic roof pressure manifested $33.8 \mathrm{~m}$ from the main longwall recovery roadway, thus the predicted next periodic roof pressure distance was $16.8 \mathrm{~m}$. The minimum mesh installation length was $12 \mathrm{~m}$. According to Equation [3], the mesh installation position should be $19.2 \mathrm{~m}$.
Therefore, the researchers suggested the mesh should be installed at $19.2 \mathrm{~m}$ instead of the empirical position of $16 \mathrm{~m}$ used previously. The mining practice indicated that the mining pressure during mesh installation was normal and the periodic roof pressure occurred at $15.5 \mathrm{~m}$ when the mesh installation was completed. By using this procedure, roof fall was prevented.

Since then, all of the adapting roadways are decommissioned when the cover depth of longwall faces exceeds $212 \mathrm{~m}$ in the Shendong coalfield. The mesh installation positions in all longwall faces are also determined by Equation [3]. With the use of such countermeasures, no incidents of roof fall and support failure occurred when longwall faces approached the recovery roadways, which demonstrates that the proposed countermeasures are appropriate and effective.

\section{Conclusions}

The Shendong coalfield commonly adopts pre-driven longwall recovery roadways, which greatly improves the rate of extraction. The special roadways, adapting roadways, are also usually pre-driven to ensure the rapid and precise match of the longwall and recovery roadway floor. With the increase in mining depth, several support failure and roof fall incidents occurred near the longwall recovery roadway area, which posed a threat to the safety of underground personnel and the mining operation. By analysing case studies of different incidents and the mining layouts, theoretical investigations and numerical simulation were conducted. It was found that the adapting roadways were the main cause of the roof fall incidents. The adapting roadway increases the roof exposure area and divide the coal mass in front of the longwall face into several separate coal pillars. This dramatically increases deformation of the coal mass and roof 


\section{Mechanism and control of roof fall and support failure incidents}

control difficulties. When the cover depth reaches a certain value, failure of the coal mass can occur over a large area, triggering serious accidents such as roof falls and support failure.

By considering coal pillar stability and the manageability of the deformation of the roadways, the maximum applicable depth of the adapting roadways is determined to be $212 \mathrm{~m}$. A method is also proposed to determine the optimum flexible mesh installation position. This systematic approach is presented in a flow chart, which can also be applied to other mines under different conditions.

In particular, for the Shendong coalfield, studies have shown that the adapting roadways should not be used at a cover depth of more than $212 \mathrm{~m}$; and if these roadways are already pre-driven, they should be backfilled or a new main longwall recovery roadway should be excavated at the end of the adapting roadways. The optimum position of mesh installation should be chosen according to determination of mine pressure, and the result can be different from the one determined empirically. The findings have been applied successfully to several longwall faces, with safe and smooth production and longwall moves, which demonstrated their effectiveness.

\section{Acknowledgements}

The authors would like to express their gratitude to the State Key Research Development Program of China (2016YFC0501100) and the Fundamental Research Funds for the Central Universities (2015XKMS098) for their financial support. The authors are also grateful to Shenhua Shendong Coal Group Co., Ltd. for its financial support that assisted the China University of Mining and Technology's research project and the field test, in particular Chen Sushe for his help during the field observation and Dayang Xuan for his advice.

\section{References}

BARCZAK, T.M. 2005. A retrospective assessment of longwall roof support with a focus on challenging accepted roof support concepts and design premises. Proceedings of the 25th International Conference on Ground Control in Mining, Morgantown, West Virginia, 2-4 August 2005. West Virginia University. pp. 232-243.

BARCZAK, T.M., Chen, J., and Bower, J. 2003. Pumpable roof supports: developing design criteria by measurement of the ground reaction curve. Proceedings of the 22th International Conference on Ground Control in Mining, Morgantown, West Virginia, 5-7 August 2003. West Virginia University. pp. 283-293.

BARCZAK, T.M., TADoLinI, S.C., and ZhANG, P. 2005. Evaluation of support and ground response as longwall face advances into and widens pre-driven recovery room. Proceedings of the 25th International Conference on Ground Control in Mining, Morgantown, West Virginia, 2-4 August 2005. West Virginia University. pp. 1-3.

BATCHLER, T. 2016. Analysis of the design and performance characteristics of pumpable roof supports. International Journal of Mining Science and Technology. doi:10.1016/j.ijmst.2016.10.003

BAUER, E.R. and LISTAK, J.M. 1989. Productivity and equipment removal enhancement using pre-driven longwall recovery rooms. Proceedings of the 1989 Multinational Conference on Mine Planning and Design, Lexington, Kentucky, 23-26May 1989. pp. 119-124.

CHEN, S.S. 2014. Dynamic mine strata pressure control technology of fullmechanized coal mining face passing through concentrated coal pillars in above seam. Coal Science and Technology, vol. 42, no. 6. pp. 140-143.
Chen, Y.G. And Lu, S.L. 1994. Strata Control Coal Mine Roadways in China. China University of Mining and Technology Press, Xuzhou. pp. 51-52.

Hou, Z.J. 2000. Analysis of combinatorial key strata stability in shallow coal seam with thick loose bed. Journal of China Coal Society, vol. 25, no. 2. pp. 127-131.

HuANG, Q.X. 2002. Ground pressure behavior and definition of shallow seams. Chinese Journal of Rock Mechanics and Engineering, vol. 21, no. 8. pp. 1174-1177.

Ju, J.F. and Xu, J.L. 2013. Prevention measures for support crushing while mining out the upper coal pillar in close distance shallow seams. Journal of Mining and Safety Engineering, vol. 30, no. 3. pp. 323-330.

Ju, J.F., Xu, J.L., and ZHU, W.B. 2015. LONGWALL CHOCK SUDDEN CLOSURE INCIDENT below coal pillar of adjacent upper mined coal seam under shallow cover in the Shendong coalfield. International Journal of Rock Mechanics and Mining Sciences, vol. 77. pp. 192-201.

KAnG, H., Lv, H., ZhANG, X., GAO, F., Wu, Z., and WANG, Z. 2015. Evaluation of the ground response of a pre-driven longwall recovery room supported by concrete cribs. Rock Mechanics and Rock Engineering, vol. 49, no. 3. pp. 1-16.

Liu, X.Q. and Chen, S.S. 1999. Application of technology of pre-driven recovery rooms in fully mechanized coal mining faces. China Coal, vol. 25, no. 10. pp. 36-37.

Lu, H.W. 2014. The mechanism of stability of pre-driven rooms and the practical techniques. Journal of China Coal Society, vol. 39, no. SI. pp. 50-56.

QIAN, M.G., SHI, P.W., and Xu, J.L. 2010. Ground Pressure and Strata Control. China University of Mining and Technology Press, Xuzhou, pp. 221-222.

SHI, P.W. and Hou, Z.J. 1996. Law of roof breaking movement of shallow seams in Shenfu CMA. Journal of Xi'an Mining Institute, vol. 16, no. 3. pp. 204-207.

TADOLINI, S.C. and BARCZAK, T.M. 2006. Design parameters of roof support systems for pre-driven longwall recovery rooms. Transactions of the Society for Mining Metallurgy and Exploration, vol. 318. pp. 87.

TADOLINI, S.C. and BARCZAK, T.M. 2001.Rock mass behavior and support response in a longwall panel pre-driven recovery room. Proceedings of the 6th International Symposium on Ground Support in Mining and Civil Engineering Construction, Cape Town, South Africa, 30 March-3 April 2008. Southern African Institute of Mining and Metallurgy, Johannesburg. pp. 167-182.

Tadolin, S.C., Zhang, Y., and Peng, S. 2002. Pre-driven experimental longwall recovery room under weak roof conditions-design, implementation, and evaluation. Proceedings of the 21st International Conference on Ground Control in Mining, Morgantown, West Virginia, 6-8 August 2002. West Virginia University. pp. 1-10.

Wichlacz, D., Britten, T., and BeAmish, B. 2009. Development of a pre-driven recovery evaluation program for longwall operations. Coal 2009: Proceedings of the Coal Operators' Conference, Wollongong, New South Wales, 12-13 February 2009. Aziz, N. (ed.). University of Wollongong and the Australasian Institute of Mining and Metallurgy. pp. 23-36.

Xu, J.L., ZHu, W.B., WANG, X.Z., and YI, M.S. 2009. Classification of key strata structure of overlying strata in shallow coal seam. Journal of China Coal Society, vol. 34, no. 7. pp. 865-870.

XU, J.L., ZHU, W.B., WANG, X.Z., and ZHANG, Z.J. 2012. Influencing mechanism of gully terrain on ground pressure behaviors in shallow seam longwall mining. Journal of China Coal Society, vol. 37, no. 2. pp. 79-85.

Zhang, P., Mishra, M., Trackemas, J., Zeglen, E., Huff, C., Peng, S.S., and Chen, J. 2006. Pre-driven longwall recovery room under weak roof conditionsdesign, evaluation, and monitoring. Proceedings of the 25th International Conference on Ground Control in Mining, Morgantown, West Virginia, 2-4 August 2005. West Virginia University. pp. 221-228.

ZHU, W.B. 2011. Study on the instability mechanism of key strata structure in repeating mining of shallow close distance seams. Journal of China Coal Society, vol. 36, no. 6. pp. 1065-1066. 